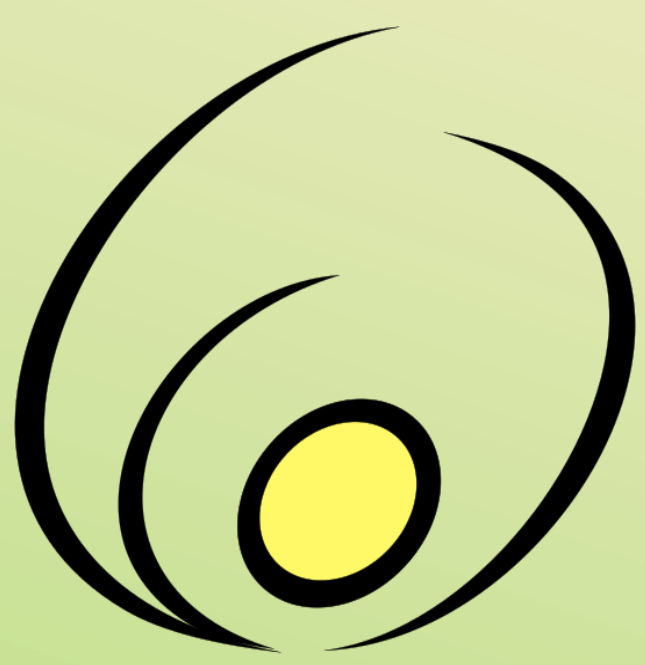

Fórum de

\section{Pró-Reitores}

\section{de Extensão}

\section{das Instituições}

Públicas de

\section{Educação Superior}

Brasileiras
Open access $\delta$ free available online

Revista Brasileira de Extensão Universitária

v. 9, n. 1, p. 27-37 jan.- abr. 2018 e-ISSN 2358-0399

DOI: https://doi.org/10.24317/2358-0399.2018v9i1.6810

\title{
Abordagem lúdica sobre os aspectos celulares do diabetes e da obesidade para alunos do ensino médio
}

\author{
Ludimila Canuto Faccioni $^{1}$ \\ Rafaela Rós Soler ${ }^{2}$
}

Resumo: A obesidade e o diabetes são consideradas doenças de alta incidência entre jovens. As causas são atribuídas ao consumo alimentar inadequado e ao sedentarismo, associados à pré-disposição genética e às alterações celulares. $O$ presente projeto propôs trabalhar o conhecimento sobre a gênese celular dessas doenças por meio da produção de atividades lúdicas e didáticas, desenvolvidas por uma equipe constituída principalmente por graduandos de Medicina da UFMS, Campo Grande, tendo como público-alvo os alunos do Ensino Médio. Termos celulares associados ao diabetes, obesidade e à nutrição foram selecionados e transformados em uma abordagem simples, didática e adequada para o entendimento dos escolares. Elementos como receptores, transportadores, enzimas e hormônios envolvidos no desenvolvimento dessas doenças foram o foco da construção das atividades. As sequencias didáticas desenvolvidas incluíram: modelos em EVA simulando células como adipócitos, enterócitos e células Beta pancreática, teatro participativo usando uma célula gigantesca para simulação dos mecanismos regidos pela insulina, apresentação de depoimento de indivíduos diabéticos, montagem de uma cozinha-cenário para jogo da verdade sobre nutrição, maquete sobre hipertrofia e hiperplasia adiposa, banner ilustrativo sobre o controle da saciedade, vídeo Draw the life que demonstra a circulação de lipídeos no organismo, uso de microscópios para demonstração do tecido adiposo e jogo de tabuleiro sobre termos celulares. As abordagens lúdicas e didáticas, desenvolvidas sobre a gênese celular das doenças e criadas como ação estratégica para o enfrentamento do diabetes e da obesidade, incentivaram a participação voluntária do públicoalvo e permitiram observar o quanto este carece de informações biológicas sobre as doenças abordadas.

Palavras-chave: Metodologias Didáticas, Doença Crônica Não Transmissivel, Extensão Universitária.

Content shared under Creative Commons Attribution 4.0 Licence CC-BY

1 Professora Doutora e Coordenadora do Projeto de Extensão. Setor de Histologia do Instituto de Biociências - INBIO, Universidade Federal do Mato Grosso do Sul - UFMS. Av. Costa e Silva, s/n, Bairro Universitário, 79070-900, Campo Grande, MS, Brasil. ludimila.faccioni@ufms.br (autora para correspondência).

2 Graduada em Ciências Biológicas - Licenciatura, Setor de Histologia do Instituto de Biociências - INBIO, UFMS. rafaelasoler@hotmail.com 


\title{
Ludic approach on the cell aspects of diabetes and obesity for high school students
}

\begin{abstract}
Diabetes and obesity are considered diseases of high incidence among young people. The causes are linked to inadequate food intake and sedentary lifestyle, associated with genetic predisposition and cell alterations. This project aimed to teach knowledge about the cell genesis of these diseases through the production of play activities and didactic activities created by a team consisting mainly of undergraduates in Medicine from UFMS, Campo Grande, targeting high school students. Cell nomenclatures associated with diabetes, obesity and nutrition were selected and modified into a simple, didactic and proper approach to facilitate the understanding of the students. Cell elements like receptors, transporters, enzymes and hormones directly involved in the development of these diseases were used as the focus of the production of the activities. The didactic sequence developed included EVA models simulating adipocyte, enterocyte and pancreatic B cells, interactive theatre using a giant cell for simulating the mechanisms controlled by insulin, testimonial of diabetic individuals, setting up a kitchen scenario for truth or dare game about nutrition, model on hypertrophy and adipose hyperplasia, illustrative banner on control of the satiety, Draw the life video demonstrating the circulation of lipids in the body, use of microscopes for demonstration of adipose tissue and board game on cell nomenclatures. The ludic and didactic approaches developed on the cell genesis of the diseases were elaborate as a strategic action to confront diabetes and obesity, and encouraged the voluntary participation of the target audience and allowed to observe their absence of knowledge of the biological information about these diseases.
\end{abstract}

Keywords: Didactic Methodologies, Non-Transmissible Chronic Diseases, University Extension

\section{Abordaje lúdico sobre los aspectos celulares de la diabetes e la obesidad para alumnos de educación secundaria}

Resumen: La obesidad y la diabetes son enfermedades consideradas de alta prevalencia entre los jóvenes. Las causas son una alimentación inadecuada y el sedentarismo, asociados a factores de riesgo genético e a las alteraciones celulares. El proyecto plantea la divulgación de conocimientos relacionados a la génesis celular de estas enfermedades a través de la realización de actividades lúdicas y didácticas creadas por un equipo formado principalmente por estudiantes de pregrado de Medicina de la UFMS, Campo Grande, y están dirigidos a alumnos de nivel secundario de Educación Básica. Términos celulares relacionados a la diabetes, obesidad y nutrición fueron seleccionados y replanteados de una manera simple, didáctica y adecuada para el entendimiento de los estudiantes. Los términos como receptores, transportadores, enzimas y hormonas relacionados con estas enfermedades fueron elegidos para la elaboración de las actividades. Las secuencias didácticas desarrolladas incluyeron: modelos en EVA simulando células como adipocitos, enterocitos y célula beta pancreática, teatro participativo con células gigantes para la simulación de los mecanismos regidos por la insulina, presentación de testimonios de individuos diabéticos, montaje de una cocina de escenario para juego de verdades y mitos acerca de la nutrición, maqueta sobre hipertrofia e hiperplasia adiposa, poster ilustrativo sobre el control de la saciedad, video de tipo Draw the life para mostrar la circulación de los lípidos en el organismo, uso de microscopios para observación del tejido adiposo y juegos de tablero de términos celulares. Los enfoques lúdicos y didácticos desarrollados sobre la génesis celular de estas enfermedades fueron creados como acción estratégica para enfrentar la diabetes y la obesidad, incentivaron la participación voluntaria del público al cual estaban dirigidas las actividades y permitieron observar la falta de informaciones biológicas sobre las enfermedades estudiadas por parte de este público.

Palabras-clave Metodologías Didácticas, Enfermedades Crónicas no Trasmisibles, Extensión Universitaria

\section{Introdução}

Enfrentamento do diabetes e obesidade por meio da educação

A obesidade e diabetes, conhecidas como doenças crônicas não transmissíveis (DCNTs), têm se apresentado como fruto de um processo histórico de mudanças nos padrões nutricionais (ORGANIZAÇÃO PAN-
AMERICANA DA SAÚDE, 2003; SOUZA; HARDT, 2012) e no comportamento sedentário da população mundial (SÃO PAULO, 2008; WHO, 2014), com consequente desregulação celular e fisiológica do organismo (JUNQUEIRA; CARNEIRO, 2013). Essas doenças têm se tornado crescente em crianças e jovens (OLIVEIRA; FISBERG, 2003).

Na educação, uma das oportunidades de ação contra essas DCNTs é por meio da capacitação dos educadores e da realização de atividades para contenção da expansão 
dessas doenças (BRASIL, 2011). Segundo Goulart (2011), uma das formas de conter essa expansão é a prevenção inovadora e efetiva que foque na prevenção primária, ou seja, em ações que visam evitar a doença na população.

O diabetes e a obesidade são temas ligados à saúde e, de acordo com os Parâmetros Curriculares Nacionais (PCN) do Ensino Fundamental do Ministério da Educação (MEC), a temática saúde deve ser desenvolvida de forma transversal, por envolver problemáticas sociais que são de grande relevância no país (BRASIL, 1998).

Quando o aluno avança para o Ensino Médio, o assunto saúde não deixa de ser relevante (BRASIL, 2000). Nesta fase da educação básica, o aluno pode assimilar ainda melhor o estado de saúde, uma vez que ao final do primeiro ano ele estudou os aspectos bioquímicos, citológicos e morfológicos do organismo humano, permitindo-o construir o conceito sistematizado de célula e tecido formador do organismo: um sistema que troca substâncias com o meio, obtém energia e que pode ser afetado por esse mesmo meio e adoecer (BRASIL, 1997).

O diabetes e a obesidade têm a sua gênese na célula, por meio de processos alterados que desregulam a assimilação de glicose, com consequentes prejuízos para o organismo (AL-GOBLAN et al., 2014). Essas doenças são abordadas em textos complementares de alguns livros didáticos de Biologia para o Ensino Médio (AMABIS; MARTHO, 2010; LINHARES; GEWANDSZNAJDER, 2012), porém, segundo Mainardi (2010), na maioria dos casos, o tema é repassado de forma conteudista aos alunos.

Dada a importância dessas doenças modernas, é comum observar projetos dirigidos por professores e extensionistas na rede pública de ensino (WAITEMAN et al., 2015; ROLINHO et al., 2016) que trabalham as informações gerais sobre a obesidade e diabetes predominantemente por meio de palestras.

O conhecimento sobre a unidade celular, trabalhado no $1^{\circ}$ ano do Ensino Médio, bem como a conscientização precoce da importância da nutrição e de bons hábitos para o correto funcionamento celular podem ser considerados aliados na prevenção do diabetes e da obesidade, tendo em vista que colabora para o esclarecimento sobre a gênese dessas doenças e a sua relação celular com os sintomas e o tratamento.

A prevenção exige conhecimento e o conhecer requer estratégias de ensino e de aprendizagem elaboradas para garantir a atenção e o interesse do aluno. Um estudo, não muito recente, apontou que apenas $20 \%$ do conteúdo repassado oralmente é assimilado. Quando a metodologia adotada envolve a audição e o visual, a assimilação passa a $40 \%$, enquanto que ter papel ativo no processo de construção do próprio conhecimento levam a retenção de $75 \%$ das informações trabalhadas (OBLINGER, 1993). Nessa perspectiva, diversas ferramentas devem ser consideradas para que o aluno escolha, entre muitos caminhos, o que mais se aproxima aos seus valores e à sua visão de mundo (ARAÚJO, 2012).
A ludicidade é um recurso pedagógico muito discutido para a promoção da aprendizagem, por permitir diferentes estímulos ao aluno, no âmbito cognitivo, emocional e do prazer. Esse recurso pode despertar o interesse do aluno levando-o a aquisição de conhecimentos por meio da exploração de diversos sentidos e de maneira agradável (ARAÚJO, 2012). A ludicidade é inerente à criança e ao jovem e propicia um maior empenho e envolvimento dos alunos em atividades didáticas (ANTUNES, 2002). No entanto, ela deve permear um conjunto de atividades ordenadas, estruturadas e articuladas para a realização de um objetivo específico na educação, caracterizando uma sequência didática (ZABALA, 1998).

$\mathrm{O}$ ambiente de ensino e aprendizagem tem um papel crucial na abordagem sobre doenças modernas, uma vez que trabalha com os indivíduos no período de formação de seus hábitos, comportamentos e opiniões, além deles serem multiplicadores de informações na comunidade e na família.

Nesse sentido, o presente projeto propôs um processo educativo como ação estratégica para o enfrentamento do diabetes e da obesidade, por meio de atividades didáticas e lúdicas diversas que transformam os aspectos celulares envolvidos na gênese dessas doenças em uma abordagem simples, didática e adequada para o entendimento de jovens escolares.

\section{Uma breve história sobre o projeto}

O Projeto de Extensão: "A célula e a origem da doença: um tema médico desafiador para o Ensino Médio" foi idealizado em 2015 quando, durante as aulas no módulo de Citologia da disciplina de Morfologia Básica para o Curso de Medicina (FAMED), sentiu-se a necessidade de ministrar conteúdos associados aos mecanismos celulares das doenças crônicas não transmissíveis (DCNTs), a fim de deixar a aula mais aplicada e voltada aos interesses dos alunos desse curso. Como a prevenção das DCNTs preconiza uma nutrição equilibrada e atividade física, foram trabalhados os aspectos celulares desse processo. A nova abordagem tornou-se interessante e aceita pelos alunos e, então, foi sendo construída a ideia de explicar DCNTs, sob a ótica celular, também aos estudantes do Ensino Médio. Para o Ensino Médio, a ludicidade foi o aspecto preponderante para a construção do projeto que, posteriormente, foi cadastrado e aprovado pelo Edital PAEXT/2016, recomendado pela coordenadoria de Extensão/PREAE e financiado pela Universidade Federal do Mato Grosso do Sul (UFMS) de Campo Grande.

Em 2016, o desafio do projeto consistiu na criação de atividades diversas sobre o aspecto celular do diabetes e da obesidade por graduandos do curso de Medicina para alunos do $1^{\mathrm{o}}$ ano do Ensino Médio. Por este motivo, o título do Projeto de Extensão veio a ser "A célula e a origem da doença: um tema médico desafiador para o Ensino Médio".

O projeto agregou 22 alunos da UFMS de Campo Grande, MS, sendo 17 graduandos do curso de Medicina, três do curso de Nutrição, um do curso de Artes e um do 
curso de Biologia. O projeto teve como sede a Casa da Ciência da Universidade Federal do Mato Grosso do Sul - Campo Grande - na qual os alunos de Escola Estadual foram recebidos para participação das atividades propostas pela equipe do projeto.

Ambientes facilitadores do ensino sobre a gênese celular do diabetes e da obesidade foram desenvolvidos para estimular a apropriação de conhecimento, conscientização e prevenção dessas DCNTs pelos jovens escolares.

\section{Métodos}

A equipe do projeto, formada por 22 graduandos, em sua maioria da Faculdade de Medicina (FAMED) e do Instituto de Biociências - INBIO), convidou alunos do $1^{\text {o }}$ ano do Ensino Médio da Escola Estadual Dona Consuelo Muller da cidade de Campo Grande, MS, para participarem das diversas atividades diversas sobre o diabetes e a obesidade, na Casa da Ciência.

Inicialmente, para o desenvolvimento das atividades, a equipe do projeto analisou o livro didático de Biologia (LINHARES; GEWANDSZNAJDER, 2012) adotado pela escola convidada, o livro de Biologia Celular do Ensino Superior dos autores Junqueira e Carneiro (2013), além de livros e artigos científicos internacionais sobre o diabetes e a obesidade (AL-GOBLAN et al., 2014). Considerando o público alvo como do $1^{\circ}$ ano do Ensino Médio, foram selecionados aqueles conteúdos científicos relevantes e construído um mapa conceitual (ONTORIA et al., 2008), no qual foram embasadas as atividades desenvolvidas. Na figura 1.a consta o registro da equipe no momento em que estudavam os conteúdos a serem trabalhados no desenvolvimento das atividades.

\section{Sobre os conteúdos escolhidos}

Em relação aos aspectos abordados sobre diabetes, foi elencado o consumo do carboidrato e sua trajetória no organismo, desde a mastigação até a sua internalização e o processamento na célula. Nesse processo, células importantes como o enterócito, que leva a glicose para o sangue, a célula beta pancreática, que se sensibiliza pela glicose circulante e libera a insulina, a célula adiposa e a célula muscular, que responde à insulina translocando os transportadores de glicose para a membrana, foram destaques, enfatizando que as falhas nos processos celulares dessas são os desencadeadoras do diabetes. Os sintomas do diabetes mellitus (DM) tipo I e II e o tipo de nutrição para prevenção e tratamento da doença também foram enfatizados.

Em relação à obesidade, os pontos centrais foram os aspetos morfológicos do tecido adiposo unilocular, os hormônios que as células desse tecido produzem e o seu papel na saciedade, a forma de absorção de gordura associados à atuação da insulina e os aspectos hiperplásicos e hipertróficos desse tecido.
Para ambas as DCNTs foram trabalhadas a importância da ingestão dos alimentos, tendo em vista que um organismo sadio é resultante de processos celulares equilibrados (GUYTON; HALL, 2006) e partindo-se do pressuposto que a célula em homeostasia é bem nutrida em qualidade e, portanto, menos propensa a ter disfunções que culminem em uma DCNT, como o diabetes ou a obesidade.

Em reuniões quinzenais, que perduraram de março a novembro de 2016, os integrantes do projeto idealizaram, planejaram e construíram diversos tipos de atividades didáticas e lúdicas, utilizando-se de ferramentas como modelos bi e tridimensionais (Figura 1.b), dinâmicas (Figura 1.c), depoimentos (Figura 1.d), jogo (Figura 1.e) e infográfico (Figura 1.f) sobre os aspectos celulares normais e à gênese do diabetes e da obesidade.

Em termos de materiais e instrumentos utilizados na confecção das atividades, usou-se EVA de cores variadas, tecido de lona, cola quente, papéis diversos, tesouras, isopor, tintas de cores variadas, fitas adesivas, cartolinas, banners impressos, câmera fotográfica, câmera filmadora, kit multimídia, notebooks, modelos anatômicos do sistema digestório, modelos anatômicos de órgãos afetados pelo diabetes, microscópios e lâminas histológicas de tecido adiposo.

As atividades foram organizadas em dois ambientes: uma sala temática sobre o diabetes (Figura 2) e uma sala temática sobre a obesidade (Figura 3). Cada ambiente foi constituído por etapas. Cada etapa foi conduzida por dois ou três integrantes do projeto e apresentou uma sequência didática (ZABALA, 1998).

Além do recurso financeiro obtido por meio do Edital PAEXT/2016, a equipe do projeto teve apoio e patrocínio de empresas diversas para obtenção de materiais para construção das atividades.

\section{Resultados e Discussão}

As sequências didáticas desenvolvidas foram propostas com a intenção de instigar os alunos a resgatar termos já apropriados durante as matérias escolares, questionandoos sobre o aspecto celular do diabetes e da obesidade e, principalmente, incentivar sua participação de forma dinâmica através de ludicidade para a aquisição de novos conhecimentos para o enfrentamento dessas doenças.

A equipe do projeto desenvolveu 16 tipos diversos de atividades distribuídas em duas salas temáticas. As metodologias didáticas adotadas atuaram como instrumento facilitador no processo de ensino pelos integrantes do projeto.

O projeto recebeu uma média de 32 alunos por dia, durante cinco dias, totalizando 160 alunos. Cada sala temática recebia em torno de 16 alunos, os quais revezavam de sala ao final das etapas. 
Na etapa 1 foi utilizado um infográfico sobre diabetes. Nessa etapa inicial, foi realizada uma breve apresentação com os dados epidemiológicos sobre o diabetes (Figura 2a). Além disso, incluíram informações sobre a incidência da doença no Brasil e no mundo, suas causas, os tipos, os sintomas, os grupos de risco, a prevenção e as complicações, por meio de gráficos, esquemas e ilustrações formatados num infográfico construído pela equipe e exposto em forma de banner. Essa etapa foi uma apresentação expositiva e de rara interação com os alunos.

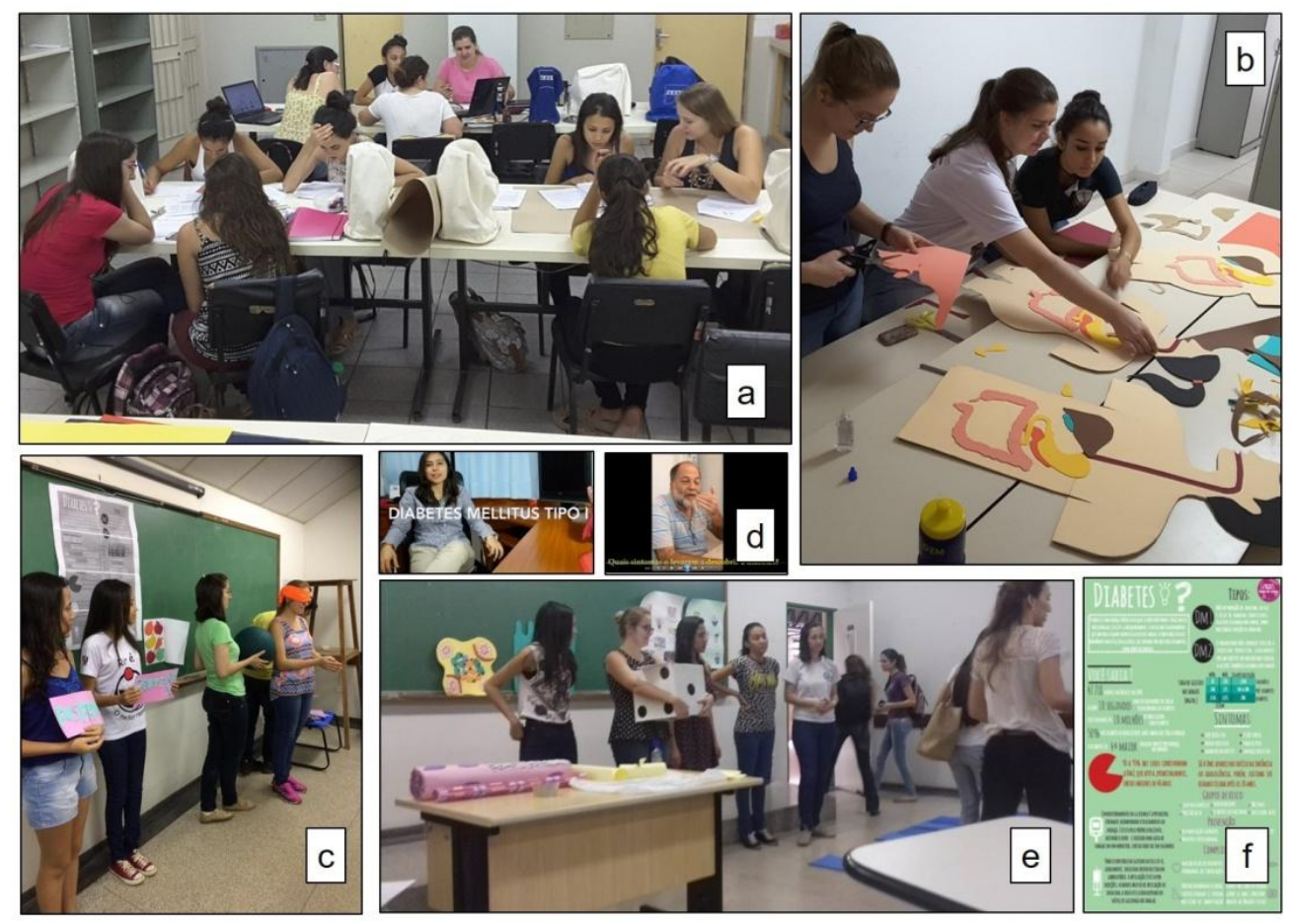

Figura 1. Equipe empenhada na idealização, planejamento e construção das atividades do projeto. Em a. Estudo sobre os aspectos celulares da diabetes e da obesidade, b. Produção de modelos em EVA (Ethylene Vinyl Acetate), c. planejamento da dinâmica, d. coleta de depoimentos de diabéticos, e. planejamento do jogo, f. infográfico finalizado sobre o diabetes.
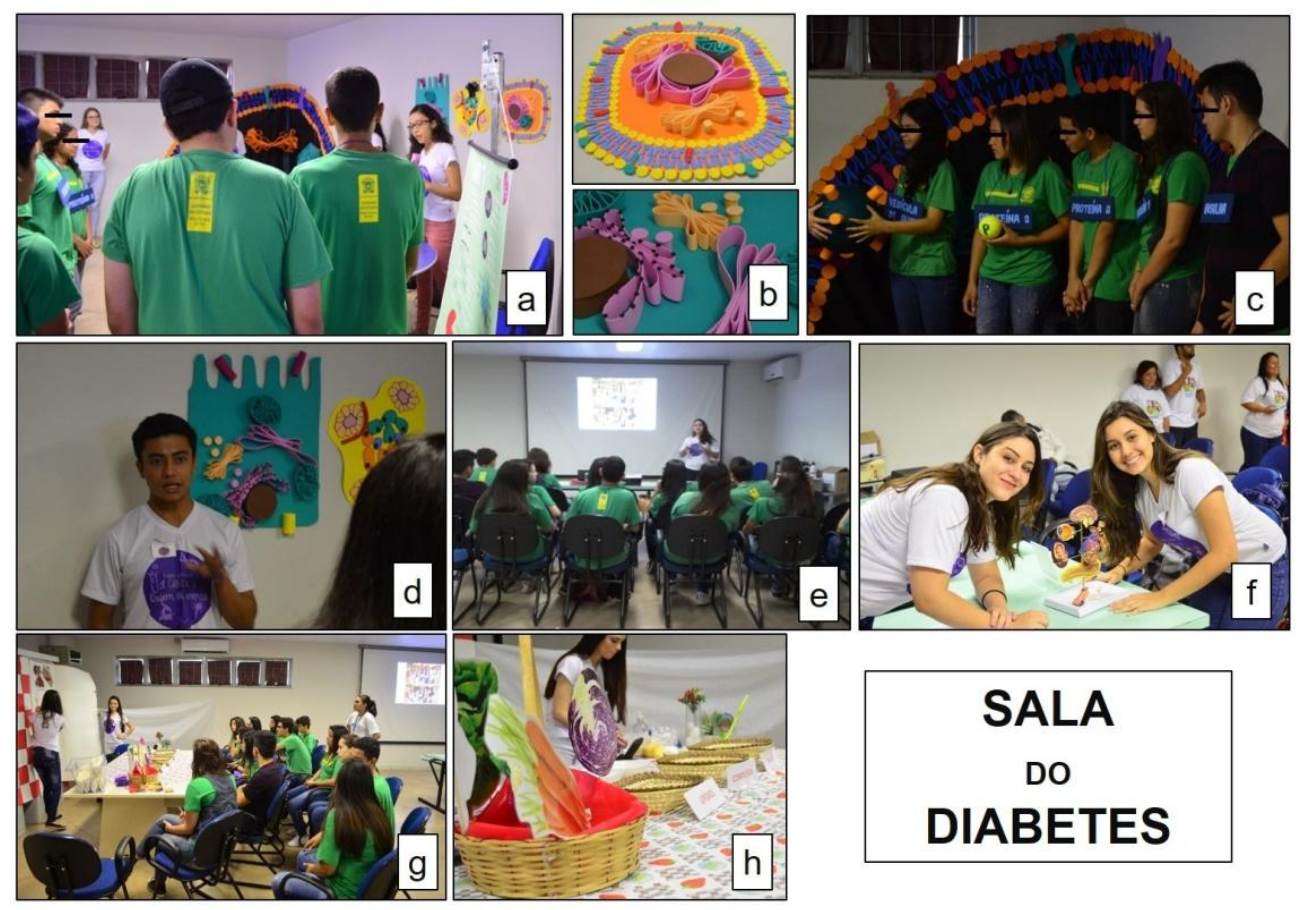

Figura 2. Etapas 1 (a) 2 (b), 3 (c), 4 (d), 5 (e), 6 (f) e 7 ( g e h) da sala temática sobre o diabetes. Fonte: Arquivos do projeto. 
Na segunda etapa, foram utilizados modelos em EVA para simular células importantes no processo de digestão, absorção do carboidrato e uso da glicose pela célula. Para essa etapa, um boneco anatômico do sistema digestório foi utilizado para nortear os alunos sobre a trajetória do carboidrato no corpo e, por conseguinte, localizar nos órgãos a presença de células como os enterócitos (intestino) e a célula Beta pancreática (pâncreas), importantes no destino da glicose no organismo. Os alunos foram sendo questionados em cada aspecto celular e fisiológico explicado, mas, embora atenciosos, pouca participação foi observada nessa etapa.

As células em EVA (Figura 2b) apresentavam morfologia compatíveis com as apresentadas pelos livros de biologia celular adotados pela equipe. O uso dessa ferramenta foi adotado, uma vez que trabalhos mostram que o uso de modelos didáticos é eficiente na apropriação do conhecimento, facilitando a assimilação de mecanismos porque envolvem memória visual e materialização das estruturas (ORLANDO et al, 2009).

$\mathrm{Na}$ terceira etapa, houve a dinâmica do mecanismo celular de absorção de glicose, na qual os alunos representaram elementos celulares desse processo, utilizando placas identificadas com os termos insulina, receptores de insulina, fosfato, proteínas intracelulares e GLUT4 (Figura 2c e Figura 3b). A simulação do processo ocorreu dentro de uma célula gigante com $2 \mathrm{~m}$ de raio (Figura 3a), a qual foi inicialmente apresentada (Figura 3b), e seus componentes funcionais foram objeto de questionamentos direcionados aos alunos (Figura 3c e 3d). Após a simulação realizada pelos participantes, esses foram questionados sobre a ausência ou disfunção de alguns elementos representados por eles, a fim de entenderem o que desencadeia o diabetes. $\mathrm{O}$ teatro ou encenação no ambiente escolar, que une conteúdo científico, arte e ensino, permeia o lúdico e o dinâmico fazendo com que o aluno passe de um papel passivo, de espectador, para ator da construção do seu próprio conhecimento, o que favorece uma apropriação duradoura (SILVA; SILVA; SOUZA, 2001) e significativa do conteúdo (SILVA; SILVA, 2013).

Os alunos ficaram entusiasmados com a célula tridimensional gigante montada na Sala de Diabetes. Houve a adesão de todos os alunos envolvidos, os quais tiraram dúvidas e responderam a pequenos questionamentos sobre o processo abordado pela equipe. Questionamentos estes relacionados às funções das organelas presentes na célula, função do hormônio insulina, função do receptor, a permeabilidade da membrana plasmática e a importância da glicose para célula. Os alunos souberam responder, antes da simulação, os aspectos relacionados às funções das organelas e, somente depois da dinâmica na célula, se dispuseram a responder sobre o processo de absorção de glicose mediada pela insulina e suas falhas, demonstrando o desconhecimento sobre mecanismos celulares envolvidos no diabetes.

$\mathrm{O}$ questionamento mostra-se como um instrumento fundamental na promoção da aprendizagem e edificação do conhecimento, visto que possibilita ao aluno participar ativamente, exteriorizar suas convicções e conhecimentos prévios, desenvolver habilidades de observação, investigação e pensamento crítico, além de aprimorar seus conceitos e atitudes, como demonstra o estudo de Schein e Coelho (2006).

$\mathrm{Na}$ etapa 4, foram trabalhadas as diferenças entre o diabetes Tipo I e Tipo II, também por meio de modelos de célula Beta pancreática e da ilhota de Langerhans confeccionados em EVA, e macrófagos, vírus Coxsackie e proteínas GAD-confeccionados em isopor (Figura 2d). Esses modelos foram manipulados pelos alunos, o que possibilitou o manuseio de um elemento palpável e que, segundo Oliveira (2005), desencadeia um fascínio maior pelo assunto abordado. Enquanto os alunos observavam os modelos, explicações pela equipe (Figura 2d) foram sendo construídas mediadas por perguntas como: "Se as células Beta forem destruídas, o que acontece com a produção de insulina?", "Se a insulina for reduzida, o que acontece com o açúcar no sangue?", "Se não houver receptores de insulina na membrana, o que acontece com a célula?". As explicações induziam os alunos às respostas corretas.

$\mathrm{Na}$ etapa 5, um vídeo com o depoimento de dois voluntários com diabetes (Tipo I e II) foi apresentado (Figura 1d e 2e). Os voluntários relataram sobre o antes e depois do diagnóstico. O vídeo, quando bem empregado, busca aproximar o tema do espectador e estimular o interesse pelo assunto retratado, levando-o a busca do saber (MORAN, 2009). A sinestesia do audiovisual torna mais proveitoso o caminho entre a transmissão e a aquisição do conhecimento (PFROMM NETO, 2001). Nessa etapa, os alunos já estavam mais adaptados ao ambiente e com a equipe do projeto, e se sentiram à vontade para partilhar suas vivências, que incluíam casos de família e conhecidos, com dramas similares aos apresentados nos depoimentos.

Logo após, na etapa 6 , foi realizada uma explanação acerca de modelos anatômicos de órgãos afetados pelo diabetes, emprestados pelo SESC (Serviço Social do Comércio do Mato Grosso do Sul). Os modelos abrangiam a célula nervosa e órgãos como o pé diabético, o rim e os vasos sanguíneos alterados pela doença (Figura 2f).

$\mathrm{Na}$ etapa 7, um bate-papo em uma cozinha cenográfica foi conduzido (Figura 2g). As duas alunas do curso de nutrição abordaram os grupos alimentares, como se alimentar corretamente no tratamento e prevenção do diabetes e sobre a utilização do glicosímetro.

Uma dinâmica com peneira (Figura 2h), para comparar a velocidade de absorção de carboidratos simples e complexos, foi utilizada para exemplificar o índice glicêmico. Os carboidratos complexos (de maior estrutura) possuem menor índice glicêmico, demoram mais para chegar até a corrente sanguínea (a farinha integral é mais difícil de passar pela peneira), por outro lado os carboidratos simples possuem maior índice glicêmico, levam menos tempo para chegar até a corrente 
sanguínea (a farinha branca é mais fácil de passar pela peneira). A peneira representava a borda em escova dos enterócitos e suas enzimas.

A analogia foi utilizada, uma vez que o processo de ensino aprendizagem pode resultar em episódios motivacionais no decorrer da aula e auxiliar na imaginação do conteúdo abordado, cujos conceitos científicos geralmente são abstratos (RAVIOLO; GARRITZ, 2008).

Em seguida, uma brincadeira sobre mitos e verdades foi realizada a partir de afirmações sobre a importância e significado dos alimentos. Nesse momento, os alunos utilizaram plaquinhas de verdadeiro e falso, e as levantavam para expor suas opiniões sobre as afirmativas. Exemplos de afirmativas: "Todo paciente portador de diabetes deve seguir o mesmo plano alimentar" ou "As carnes, ovos e queijos não contêm açúcar; podem, então, ser consumidos à vontade." Dada a complexidade do assunto, as respostas verdadeiras foram reduzidas.

Assim que terminaram as etapas da sala de diabetes, os alunos seguiram para a sala temática sobre a obesidade (Figura 3).

\section{Sequências didáticas da sala temática de obesidade}

Uma abordagem inicial sobre a doença foi realizada, considerando sua definição, suas causas, sua relação com outras enfermidades e os padrões de acúmulo de gordura em homens e mulheres, utilizando-se de modelos masculino e feminino do sistema digestório construídos em EVA, focando no excesso e na localização da gordura (Figura 3a).

Em seguida, na Etapa 2 (Figura 4b), um vídeo (Draw the life) foi apresentado abordando a importância dos lipídeos como constituinte celular (Figura 5a-b), o transporte do lipídeo através das células (Figura 5c) e o seu armazenamento em forma de gordura em adipócitos ou hepatócitos (Figura 5d). Em seguida, na Etapa 3, houve um resgate de termos do vídeo com o uso de modelos em isopor e EVA para diferenciar as lipoproteínas: quilomícron, LDL e HDL (Figura 4c). Uma explicação sobre o mau e o bom colesterol foi realizada, e foi demonstrado como estes são representados no exame de sangue. Nessa fase, os alunos puderam manipular os modelos e perceber as diferenças estruturais das lipoproteínas.
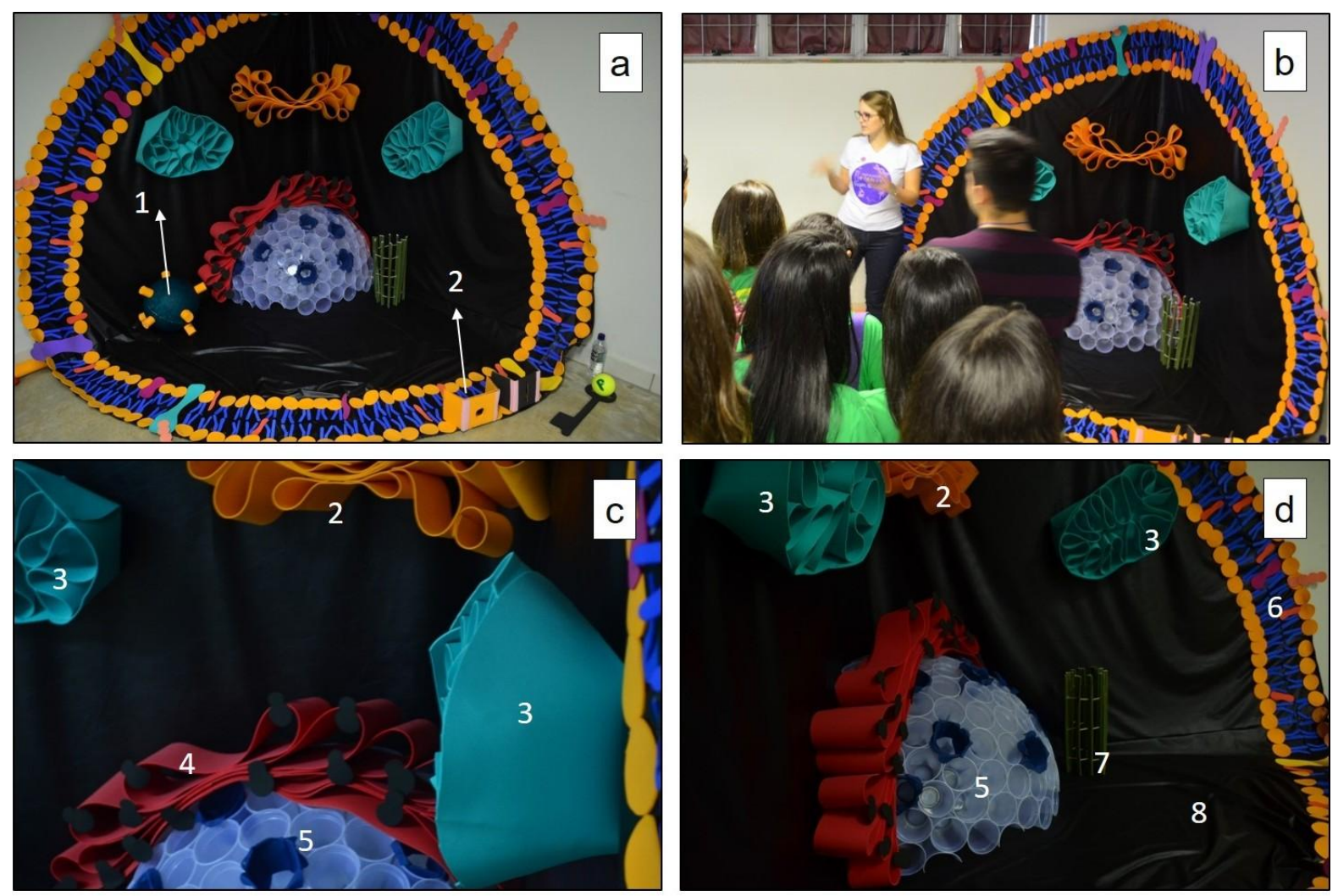

Figura 3. Representação em escala aumentada da célula e suas organelas. a. Célula gigante com raio de $2 \mathrm{~m}$ para demonstração dos mecanismos envolvidos no controle do transporte da glicosa na célula, com destaque para a vesícula de GLUT4 (1) e um receptor de insulina (2); b. dinâmica com os alunos do ensino médio; c-d. detalhes das organelas das células confeccionadas em EVA destacando o complexo de Golgi (2), as mitocôndrias (3), o retículo endoplasmático rugoso (4), o envelope nuclear e complexos de poro (5), a bicamada lipídica e proteínas inseridas (6), centríolo (7) e citoplasma (8). Fonte: arquivos do projeto. 
Segundo Orlando et. al (2009), os moldes didáticos em três dimensões ou em alto-relevo auxiliam na correlação do conteúdo teórico com o prático, além de aprimorar as habilidades de assimilação, associação e memorização.

$\mathrm{Na}$ etapa 4, a proposta foi uma recapitulação sobre a morfofisiologia do tecido adiposo. Para tanto, a constituição, tipos e função desse tecido foi apresentado, para isso, uma placa feita de EVA em relevo representando adipócitos (Figura 6b) foi demonstrada e, em seguida, os alunos puderam observar o tecido adiposo amarelo em microscópio e identificar a morfologia dos adipócitos (Figura 4d). Os alunos se mostraram entusiasmados em manipular os microscópios. A citologia aborda conceitos de caráter abstrato e que estão incorporados na perspectiva microscópica, portanto, o uso de modelos didáticos se faz necessário (ORLANDO et al. 2009) e, considerando essa perspectiva, a etapa 4 foi delineada.

$\mathrm{Na}$ etapa 5 (Figura 4e), a hiperplasia e a hipertrofia do tecido adiposo e sua relação com a hipóxia tecidual foi trabalhada com os alunos (Figura 6c). Uma maquete foi utilizada para simular a hipóxia: na medida em que as células aumentavam, comprimiam os vasos sanguíneos o que, por sua vez, diminuía a circulação, reduzindo a oxigenação nos tecidos adjacentes. Os alunos puderam manipular os vasos feitos em EVA e visualizar em grande escala o que acontece no tecido em hipóxia.
Na Etapa 6 (Figura 4f), intitulada de "Descobrindo o tecido adiposo endócrino", elementos como a leptina, a adiponectina e fatores pró-inflamatórios foram apresentados e relacionados com a quantidade de tecido adiposo e com a saciedade. Para essa etapa, um banner ilustrativo e modelos de neurônios em isopor e EVA foram utilizados (Figura 6a e 6e). Nessa etapa, os alunos puderam entender o porquê uma pessoa obesa perde o controle sobre a ingestão alimentar.

$\mathrm{Na}$ etapa 7, os alunos voluntariamente falaram seu peso e altura, previamente medidos pelos integrantes. Logo após, foi realizado o cálculo do Índice de Massa Corpóreo (IMC) e verificação da condição nutricional utilizando gráfico do Ministério da Saúde em tamanho ampliado, e este foi fixado na parede (Figura 4g). Cada aluno recebeu um cartão autoexplicativo contendo a fórmula do IMC e puderam calcular e tirar suas dúvidas.

$\mathrm{Na}$ Etapa 8, a prevenção da obesidade mediada pela alimentação foi trabalhada utilizando-se uma pirâmide gigante para exemplificar a ideia de um prato saudável e também foi ressaltada a importância da atividade física, utilizando-se a comparação entre o alimento ingerido e o exercício necessário para gastar as calorias ingeridas. Nessa última atividade, os alunos foram respondendo sobre o esporte e o alimento que achavam compatíveis.

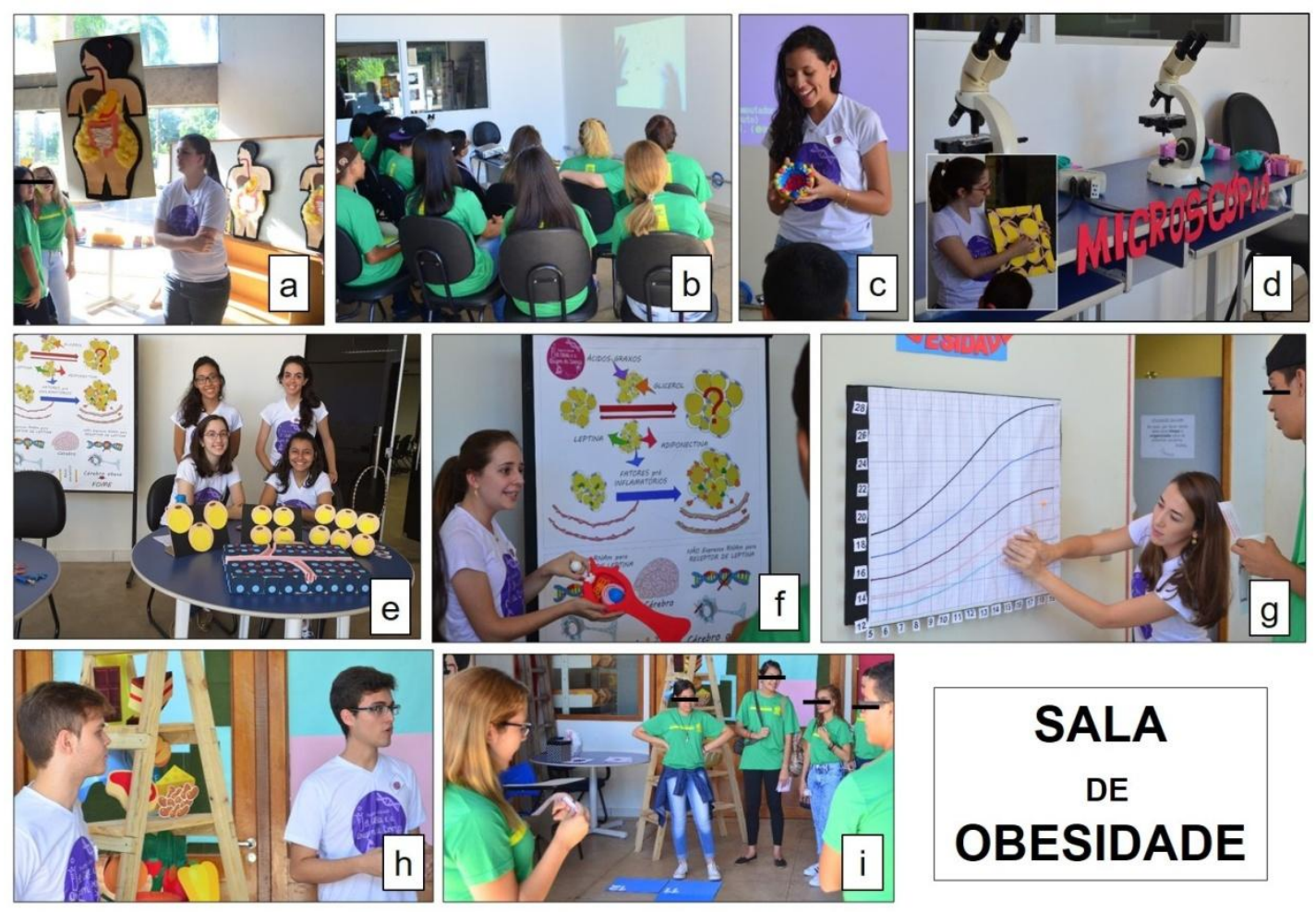

Figura 4. Etapas 1 (a) 2 (b), 3 (c), 4 (d), 5 (e), 6 (f) e 7 (g-h) da sala temática sobre a obesidade. Fonte: Arquivos do projeto. 

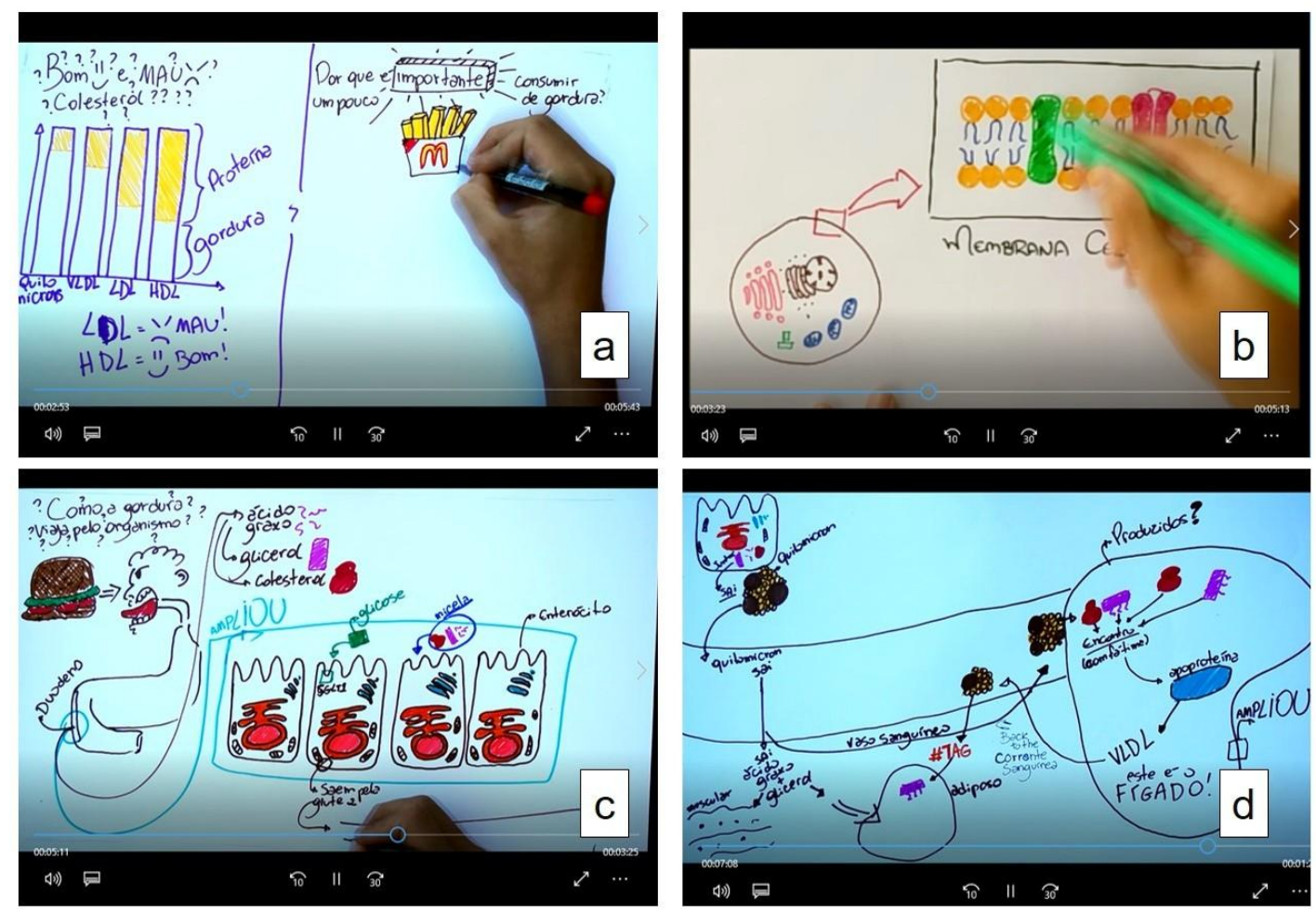

Figura 5. Produção de vídeos com base em "Draw the life", desenvolvidos e editados por membros da equipe do projeto; a-b. sobre a importância dos lipídios como constituinte celular, c. sobre o transporte de lipídios através das células e d. seu armazenamento em forma de gordura em adipócitos ou hepatócitos. Fonte: Arquivos do projeto.

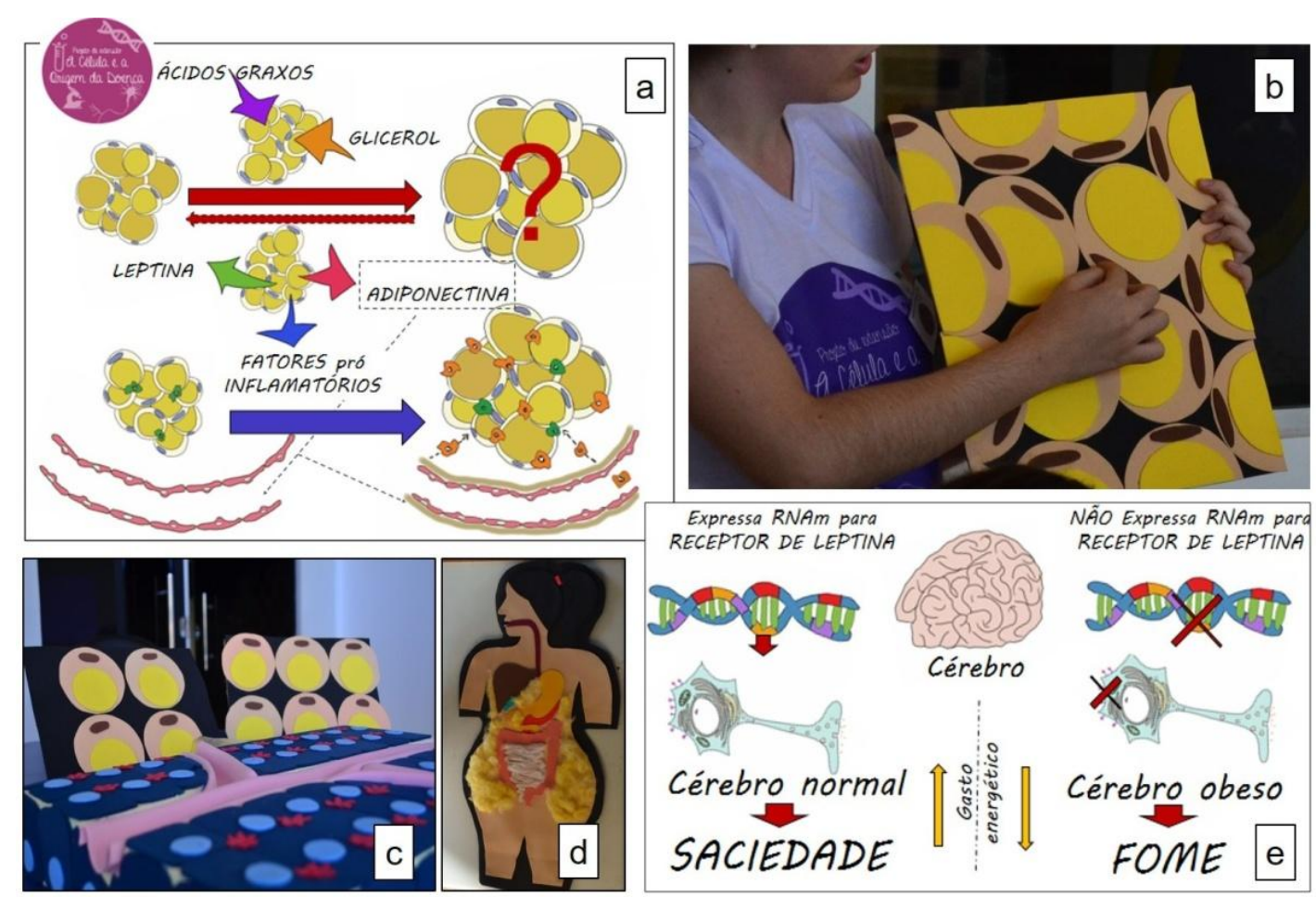

Figura 6. Materiais produzidos e usados para esclarecimentos sobre a obesidade sob o aspecto celular; a. banner sobre a importância endócrina das células adiposas uniloculares; b. morfologia das células adiposas uniloculares; c. material em relevo (maquete) sobre hiperplasia e hipertrofia das células adiposas e sua contribuição para alteração da pressão e hipóxia tecidual; $\mathbf{d}$. boneco em EVA com distribuição do tecido adiposo corpóreo feito em espuma; e. banner sobre os mecanismos de regulação da fome. 
Na última etapa (9), foi proposto um jogo de tabuleiro sobre termos abordados acerca do diabetes e da obesidade. Esse jogo permitiu à equipe do projeto fazer uma revisão sobre os termos abordados previamente nas salas temáticas. Para tanto, os alunos foram subdivididos em grupos adversários. Na medida em que o grupo respondia corretamente à pergunta realizada pela equipe do projeto, podia avançar o número de casas do tabuleiro decidido pelo jogo de dado. Quando a resposta à pergunta era errada, o grupo recebia uma advertência de forma lúdica e, em seguida, o termo era esclarecido pela equipe. Os alunos ficaram extremamente excitados com o jogo, houve participação da maioria, contudo, as respostas variaram entre corretas e erradas. Esse momento constituiu um método de destaque na transmissão e apreensão do conhecimento, principalmente os de maior complexidade e com caráter subjetivo, uma vez que estimulou a discussão e a resolução de impasses, relação interpessoal, e no caso dos erros permitiu novas tentativas, além de unir o lúdico com o cognitivo.

Apesar do projeto não prever a quantificação do número de interações dos escolares nas atividades e a assertividade dessas participações, a percepção da equipe, ao observar o envolvimento dos participantes, foi de que estes carecem de informações sobre as doenças abordadas e que se sentem estimulados a aprender mediante uma abordagem de ensino lúdica e didática.

\section{Considerações finais}

Esse projeto de extensão apresentou uma nova abordagem lúdica e didática como ação estratégica para o enfrentamento do diabetes e da obesidade, tendo em vista primeiramente, a escolha da célula como foco para a compreensão da gênese dessas doenças. Além disso, o projeto inova na medida em que se utiliza de atividades diversas para estimular a aquisição do conhecimento biológico e a reflexão, pontos de partida para a mudança de comportamento do jovem na escolha de uma vida saudável e consciente.

\section{Agradecimentos}

Ao apoio financeiro da Pró-Reitoria de Extensão, Cultura e Esportes UFMS, Edital PAEXT/2016, protocolo: 215382.1071.196415.30092015, a coordenadora do Programa Saúde nas Escolas (PSE) Soraya Solon, aos professores colaboradores Viviane Bento, Sandra S. Cereali e Jesiel Mamede Silva, à Casa da Ciência, à Escola Estadual Consuelo Muller, ao Espaço Interativo de Ciências-CIBFar/FAPESP USP, aos entrevistados Ana Luiza Cruz Abromovicios e João Franscisco Sanches, à equipe do SESC (Serviço Social do Comércio do Mato Grosso do Sul); aos patrocinadores Silas Estofado, Santa Rita Decor, Atacado Nacional, São Gonçalo Bazar, Versátil Camiseteria, AmarelinHU Lanchonete, e aos imprescindíveis integrantes e idealizadores de cada atividade do projeto: Amanda Faustini Ferreira, André Gonçalves de Souza, Bruna Zavatti Vacchiano, Fabíola Vieira de Mello, Giulia Zanotto, Isabela Rocha Rubini, Isabelle Carolina Basualdo Pedreira, Jodri Aquino, Juliana Marques Bendito, Lais Felix Batista, Maria Alice Fontoura Lima, Mário Salomão Cury Pires, Mayara Pereira Vasconselos, Raquel Dos Santos Silva, Rayssa de Sousa Matos da Costa, Roberta Rios Soares, Tais Rosa Calisto, Tássia Vieira Ávalos, Tiago Yuta Yamaguti Maziero, Vanessa Bernardes Daniel e Victor Ribeiro de Sant'Ana.

\section{Contribuição de cada autor}

L. C. F : Idealizadora e coordenadora do projeto "A célula e a origem da doença: um tema médico desafiador para o Ensino Médio", responsável pelo planejamento, coleta de dados, confecção e edição do artigo. R. R. S.: integrante do projeto, responsável pela execução e logística das atividades do projeto junto a escola, pela revisão bibliográfica e confecção do artigo.

\section{Referências}

AL-GOBLAN, A. S.; AL-ALFI, M. A.; KHAN, M. Z. Mechanism linking diabetes mellitus and obesity. Diabetes, Metabolic Syndrome and Obesity: Targets and Therapy, v. 7, n. 4, p. 587-591, 2014.

ANTUNES, C. Novas Maneiras de Ensinar - Novas formas de Aprender. Rio de Janeiro: Artmed, 2002.

AMABIS, J. M.; MARTHO, G. R. Biologia das células. 3. ed. São Paulo: Moderna, 2010.

ARAÚJO, M. S. Lúdico: aprender de forma prazerosa. Cadernos de Pesquisa (São Luís), v. 19, n. 3, p.71-78, 2012.

BRASIL. Parâmetros Curriculares Nacionais do Ensino Médio (PCNs). Biologia. Brasília: MEC/SEF, 1997.

BRASIL. Secretaria de Educação Fundamental. Parâmetros curriculares nacionais: terceiro e quarto ciclos do ensino fundamental: Temas transversais: Saúde. Brasília: MEC/SEF, 1998.

BRASIL. Parâmetros Curriculares Nacionais do Ensino Médio (PCNEM). Brasília: MEC/SEF, 2000.

BRASIL. Ministério da Saúde. Secretaria de Vigilância em Saúde. Departamento de Análise de Situação de Saúde. Plano de Ações Estratégicas para o Enfrentamento das Doenças Crônicas Não Transmissíveis (DCNT) no Brasil 2011-2022. Brasília: Ministério da Saúde, 2011. Disponível em: < http://bvsms.saude.gov.br/bvs/publicacoes/plano_acoes enfrent_dent_2011.pdf >, acesso em 10 nov. 2015.

GOULART, F. A. A. Organização Pan-Americana de Saúde. Doenças crônicas não transmissíveis: 
estratégias de controle e desafios e para os sistemas de saúde. Brasília: Ministério da Saúde, 2011.

GUYTON, A. C.; HALL, J. E. Tratado de fisiologia médica. 11. ed., Rio de Janeiro: Elsevier, 2006.

JUNQUEIRA, L. C.; CARNEIRO, J. Biologia Celular e Molecular. 11. ed., Rio de Janeiro: Guanabara Koogan, 2013.

LINHARES, S.; GEWANDSZNAJDER, F. Biologia Hoje. 2. ed., São Paulo: Ática, 2012.

MAINARDI, N. Educação em saúde: problema ou solução? Tese de Doutorado, Faculdade de Saúde Pública da Universidade de São Paulo - Brasil. São Paulo, 2010.

MORAN, J. M. A educação que desejamos: novos desafios e como chegar lá. 2. ed. Campinas, SP: Papirus, 2007.

OBLINGER, D. G. Multimedia in the classroom. Information Technology and Libraries, v. 12, n. 2, p. 246-247, 1993.

OLIVEIRA, S. S. Concepções alternativas e ensino de biologia: como utilizar estratégias diferenciadas na formação inicial de licenciados. Curitiba: Editora UFPR, 2005 .

OLIVEIRA, C. L.; FISBERG, M. Obesidade na infância e adolescência - uma verdadeira epidemia. Arquivos Brasileiros de Endocrinologia e Metabologia, v.47, n.2, p. 107-108, 2003.

ONTORIA, A.; LUQUE, Â.; GÓMEZ, J.P.R. Aprender com mapas mentais - uma estratégia para pensar e estudar. 3. ed. São Paulo: Madras, 2008.

ORGANIZAÇÃO PAN-AMERICANA DA SAÚDE. Doenças crônico degenerativas e obesidade: estratégia mundial sobre alimentação saudável, atividade física e saúde. Brasília: OPAS, 2003. Disponível em: < http://bvsms.saude.gov.br/bvs/publicacoes/doenca_cronic o_degenerativas obesidade estrategia_mundial_alimenta cao atividade fisica.pdf $>$. Acesso em: 31 ago. 2017.

ORLANDO, T. C. et al. Planejamento, montagem e aplicação de modelos didáticos para abordagem de Biologia celular e Molecular no Ensino Médio por graduandos de Ciências Biológicas. Revista Brasileira de Ensino de Bioquímica e Biologia Molecular, v. 10, p. 1-17, 2009.

PFROMM NETO, S. Telas que ensinam. Mídia e aprendizagem: do cinema ao computador. 2. ed. Campinas: Alínea, 2001.

RAVIOLO, A.; GARRITZ, A. Analogias no ensino do equilíbrio químico. Química nova na escola, n. 27, 2008.

ROLINHO, N. V. T.; VIEIRA, H. S.; NERI, D. F. M. Medicina na escola: a lição é a prevenção do diabetes. Extramuros - Revista de Extensão da UNIVASF, v. 4, n. 2, p. 66-74, 2016.

SÃO PAUlO. Prevenção de Doenças Crônicas Não Transmissíveis e seus fatores de risco
SES/CVE/DDCNT. 3. Ed. São Paulo, 2008. Disponível em: < ftp://ftp.cve.saude.sp.gov.br/doc tec/cronicas/ CARTILHA_AGSAUDE08.pdf $>$, acesso em 31 ago. 2017.

SCHEIN, Z. P.; COELHO, S. M. O papel do questionamento: intervenções do professor e do aluno na construção do conhecimento. Caderno Brasileiro de Ensino em Física, v. 23, n. 1, p. 68-92, 2006.

SILVA, R. A.; SILVA, M. L.; SOUZA, R. O ensino da anatomia através das artes cênicas. Arquivos da APEDEC, v. 5, n. 1, p. 9-14, 2001.

SILVA, F. T.; SILVA, A. L. O teatro como instrumento pedagógico para o ensino de Física. Caderno de Física da UEFS, v. 11, n. 1, p. 43-55, 2013.

SOUZA, M. D. C. A.; HARDT, P. P. Evolução dos hábitos alimentares no Brasil. Revista Online Brasil Alimentos, n. 15, pag. 32-39, 2002.

WAITEMAN, M. C. et al. Projeto de extensão: diabetes, você sabe o que é isso? In: $8^{\circ}$ Congresso de extensão universitária da UNESP, 8., 2015, Presidente Prudente. Anais eletrônicos... Presidente Prudente: UNESP, 2015. Disponível em: < http://200.145.6.205/index.php/ congressoextensão/paper/view/216/269 >, acesso em: 10 nov. 2016

WHO. Global status report on noncommunicable diseases 2014. Word Health Organization, Geneva, 2014. Disponível em: < http://apps.who.int/iris/ bitstream/10665/148114/1/9789241564854_eng.pdf >, acesso em 31 ago. 2017.

ZABALA, A. A prática educativa: como ensinar. Porto Alegre: ArtMed, 1998.

Como citar este artigo:

FACCIONI, L. C.; SOLER, R. R. Abordagem lúdica sobre os aspectos celulares do diabetes e da obesidade para alunos do ensino médio. Revista Brasileira de Extensão Universitária, v. 9, n. 1, p. 27-37, 2018. Disponível em: < https://periodicos.uffs.edu.br/index.php/RBEU/article/view/681 $\underline{0 / p d f}>$ 